\title{
3 Research Square \\ Spatiotemporal Patterns and Threshold of Chlorophyll-a in Lake Taihu Based on Microcystins
}

xuemei fu

CRAES: Chinese Research Academy of Environmental Sciences

Mingxia Zheng ( $\square$ zhengmx@craes.org.cn)

Chinese Research Academy of Environmental Sciences

Jing Su

Chinese Research Academy of Environmental Sciences

Beidou Xi

Chinese Research Academy of Environmental Sciences

Daichun Wu

Chinese Research Academy of Environmental Sciences

Xiaoli Wang

Chinese Research Academy of Environmental Sciences

\section{Research Article}

Keywords: Chlorophyll-a, microcystin, spatiotemporal pattern, chlorophyll a threshold, Lake Taihu

Posted Date: April 13th, 2021

DOl: https://doi.org/10.21203/rs.3.rs-285691/v1

License: (c) (i) This work is licensed under a Creative Commons Attribution 4.0 International License.

Read Full License 


\section{Abstract}

Chlorophyll-a (Chl-a ) is considered an indicator of phytoplankton biomass dynamically reflecting the growth of algae. Therefore, determination of $\mathrm{Chl}$ - a threshold is of vital importance to the health of aquatic ecosystems and drinking water security. This research is aimed to investigate the spatial and temporal distributions of Chl- a and microcystin (MC) concentrations using Geographic Information System (GIS) and identify the Chl- a threshold in Lake Taihu based on available guideline values of MCs. Nearly the same characteristics of spatiotemporal variation of Chl- a and MCs were observed in Lake Taihu. Overall, the lakewide distributions of Chl- a and MCs were highly variable over time and space. The Chl- a concentration in the winter and spring was relatively low, and gradually increasing in summer and autumn, with the maximum concentration observed in August. But the maximum MCs concentration appeared in October, two months lagging behind the Chl- a . The highest annual average Chl- a and MCs concentrations were observed in Zhushan Bay, Meiliang Bay, Gonghu Bay in northwest of Lake Taihu, following by West Zone and Center Zone. Dongtaihu Bay, East Zone and South Zone always present good water quality. Referring to the guideline value of MCs, the Chl- a threshold was determined as 10-15 $\mathrm{mg} \cdot \mathrm{m}-3$ based on the linear regression correlation between $\mathrm{Chl}-\mathrm{a}$ and MCs. The establishment of $\mathrm{Chl}-\mathrm{a}$ threshold is useful for eutrophication control, water quality management and drinking water utilities in developing water safety plans.

\section{Full-text}

Due to technical limitations, full-text HTML conversion of this manuscript could not be completed. However, the manuscript can be downloaded and accessed as a PDF.

\section{Figures}



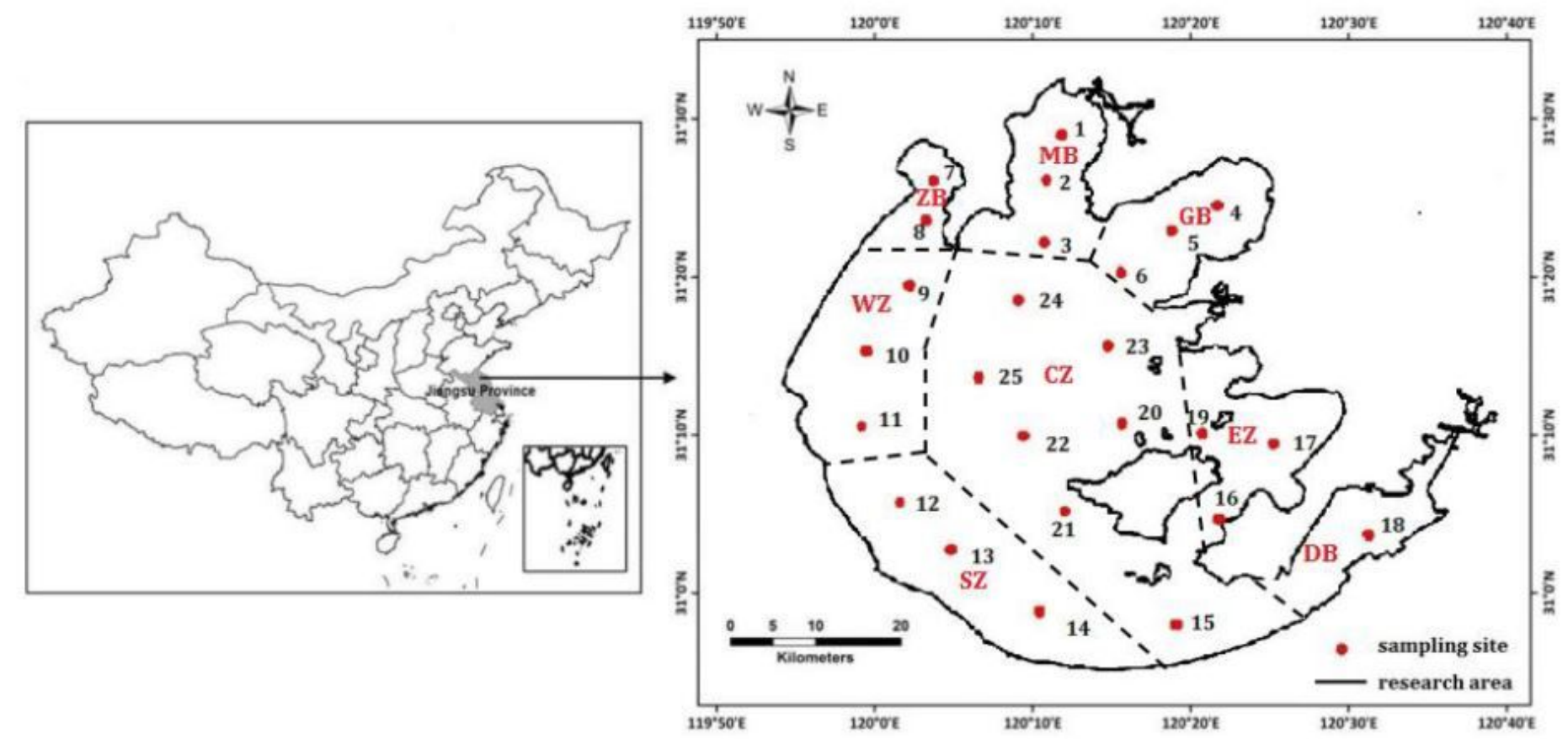

Figure 1

The geographic location of Taihu Lake and sampling sites (The lake is divided into 8 sub regions ZB: 153 Zhushan Bay; WZ: West Zone; SZ: S outh Zone; DB: Dongtaihu Bay EZ: East Zone ; GB: Gonghu Bay ; MB: 154 Meilianghu Bay; CZ: Center Zone. The figure is created by ArcGIS 10.2 (http://www.esri.com). Note: The designations employed and the presentation of the material on this map do not imply the expression of any opinion whatsoever on the part of Research Square concerning the legal status of any country, territory, city or area or of its authorities, or concerning the delimitation of its frontiers or boundaries. This map has been provided by the authors. 



\section{Figure 2}

Spatiotemporal variation of Chl-a concentration in Taihu Lake in 20132014 ((a) March (b) 241 June (c) July (d) August (e) September (f) October (g) December h Annual mean) Note: The designations employed and the presentation of the material on this map do not imply the expression of any opinion whatsoever on the part of Research Square concerning the legal status of any country, territory, city or area or of its authorities, or concerning the delimitation of its frontiers or boundaries. This map has been provided by the authors. 

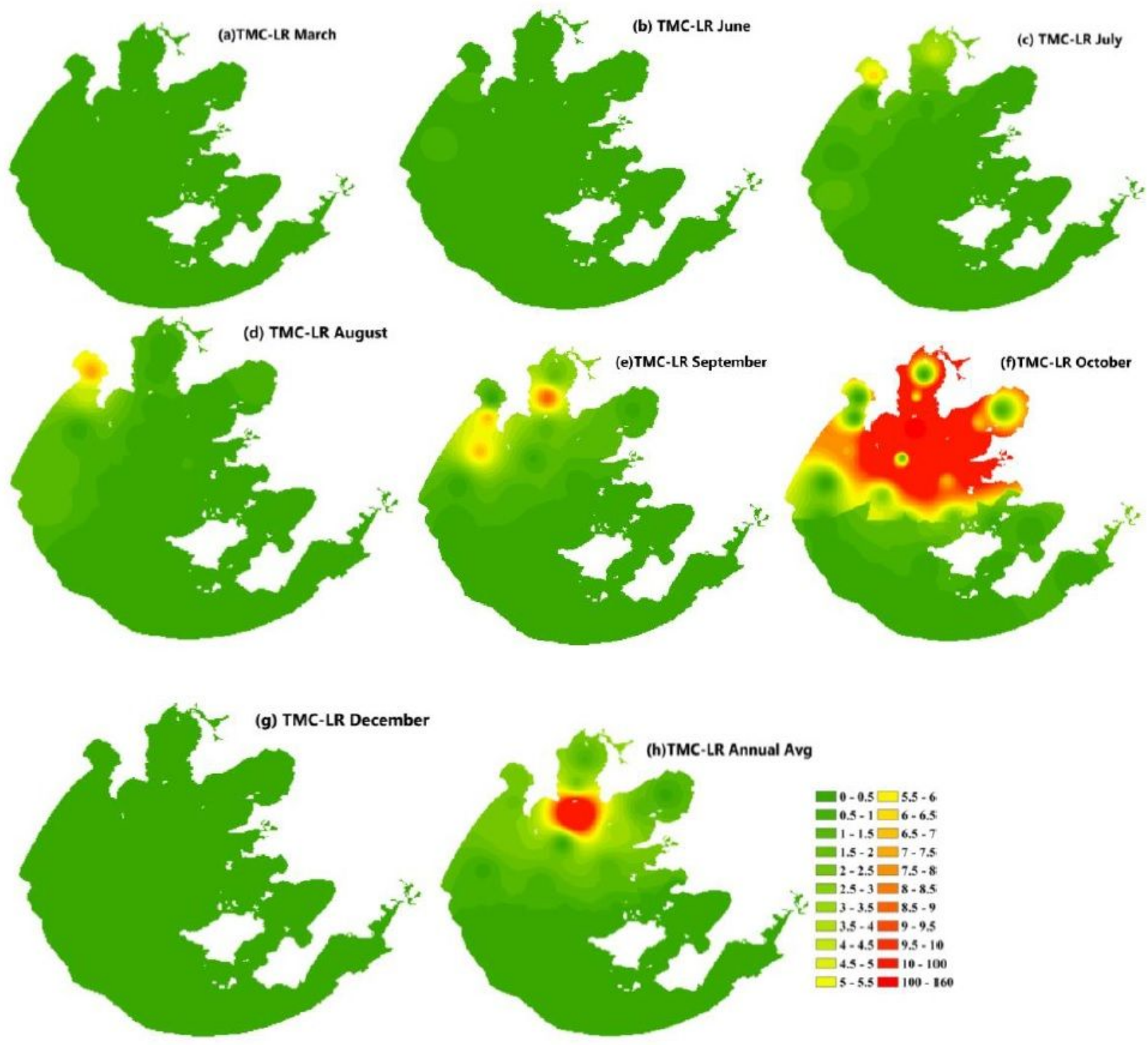

\section{Figure 3}

Spatiotemporal variation of TMC LR concentration in Taihu Lake in 2013 and 2014 ((a) 334 March (b) June (c) July (d) August (e) September (f) October (g) December (h)annual Note: The designations employed and the presentation of the material on this map do not imply the expression of any opinion whatsoever on the part of Research Square concerning the legal status of any country, territory, city or area or of its authorities, or concerning the delimitation of its frontiers or boundaries. This map has been provided by the authors. 

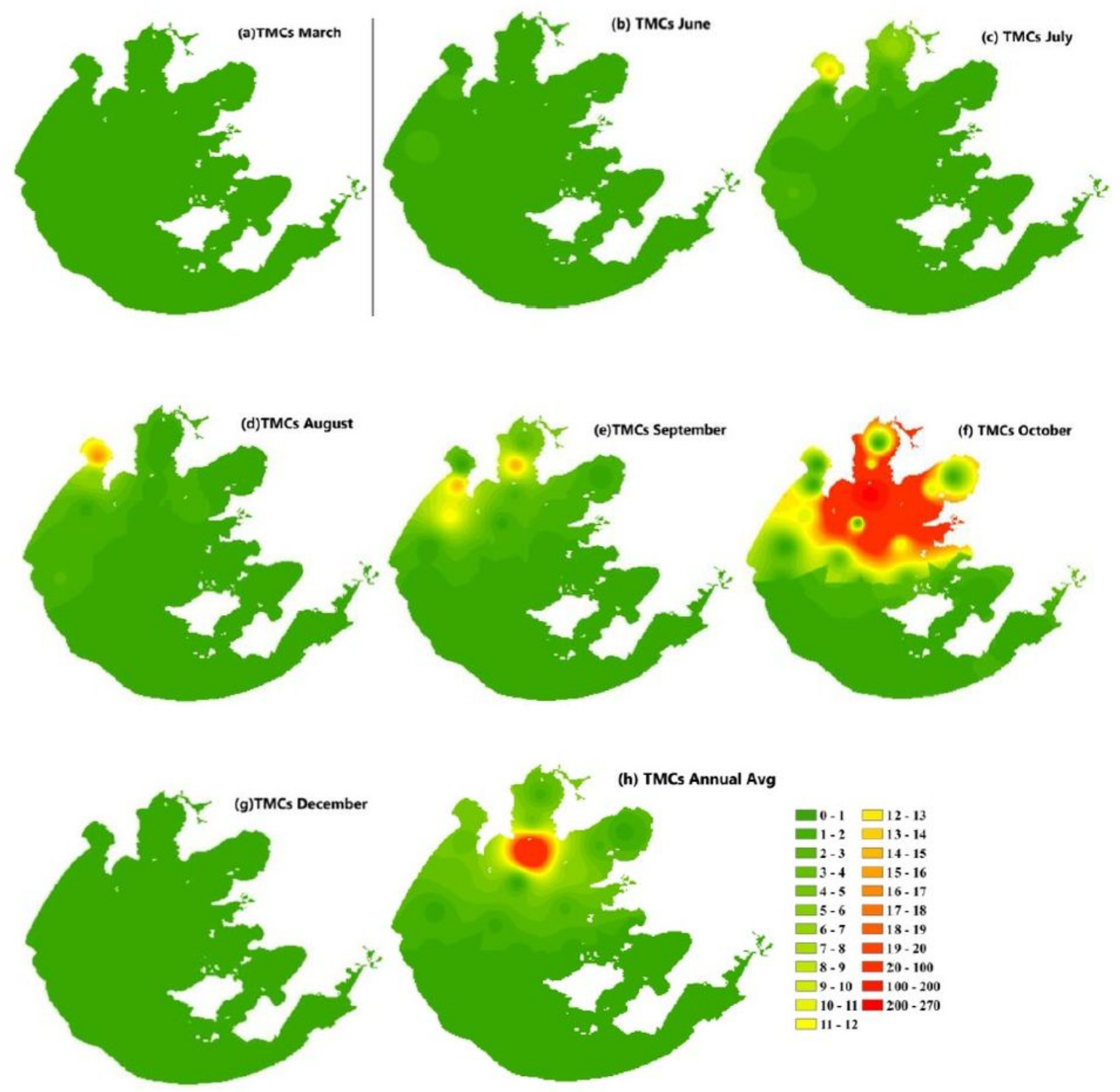

\section{Figure 4}

Spatiotemporal variation of TMCs concentration in Taihu Lake in 2013 ((a) March (b) 342 June (c) July (d) Aug ust (e) September (f) October (g) December (h) annual average). Note: The designations employed and the presentation of the material on this map do not imply the expression of any opinion whatsoever on the part of Research Square concerning the legal status of any country, territory, city or area or of its authorities, or concerning the delimitation of its frontiers or boundaries. This map has been provided by the authors. 


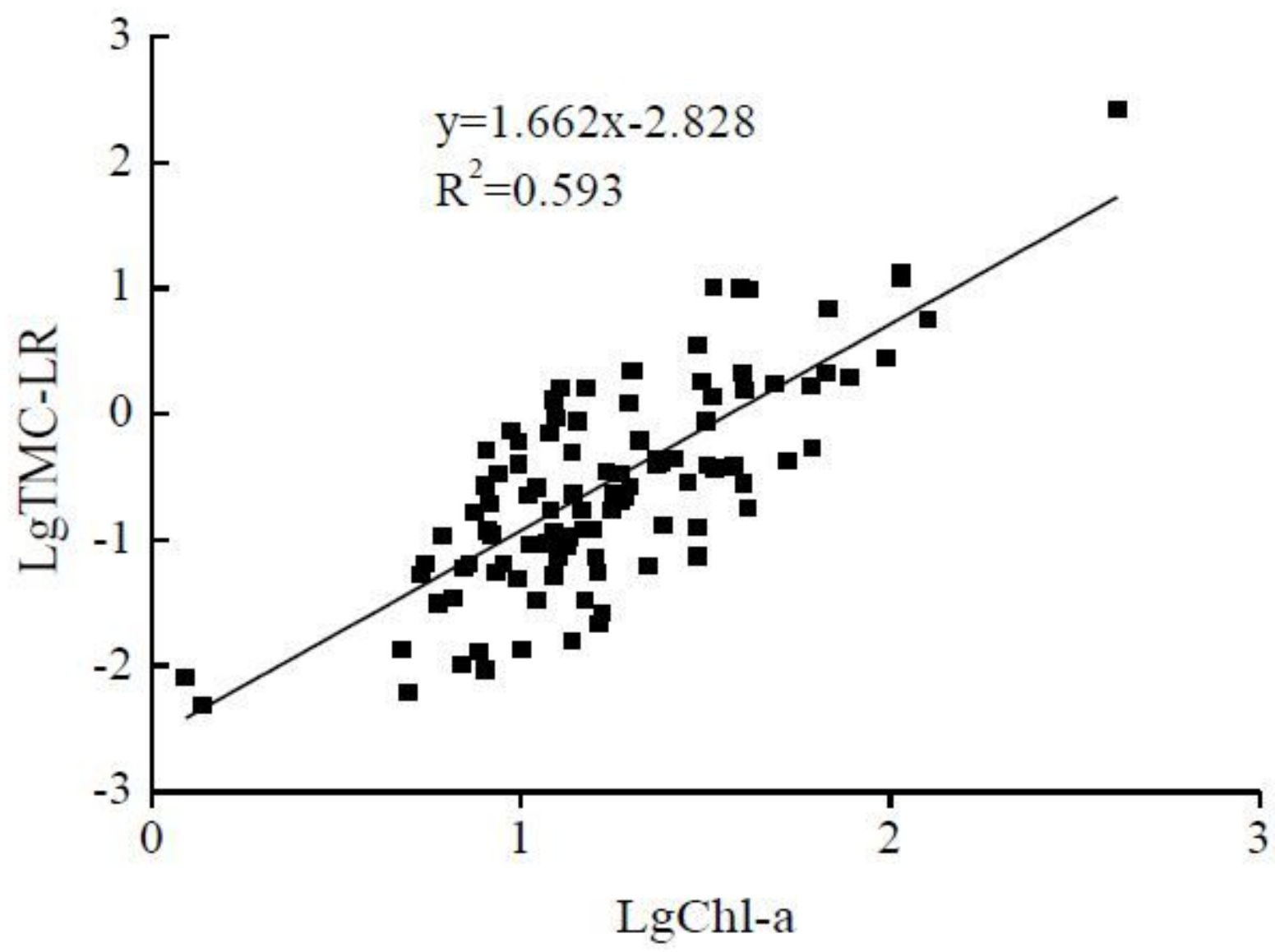

Figure 5

The correlation between TMC-LR and Chl-a of Lake Taihu 


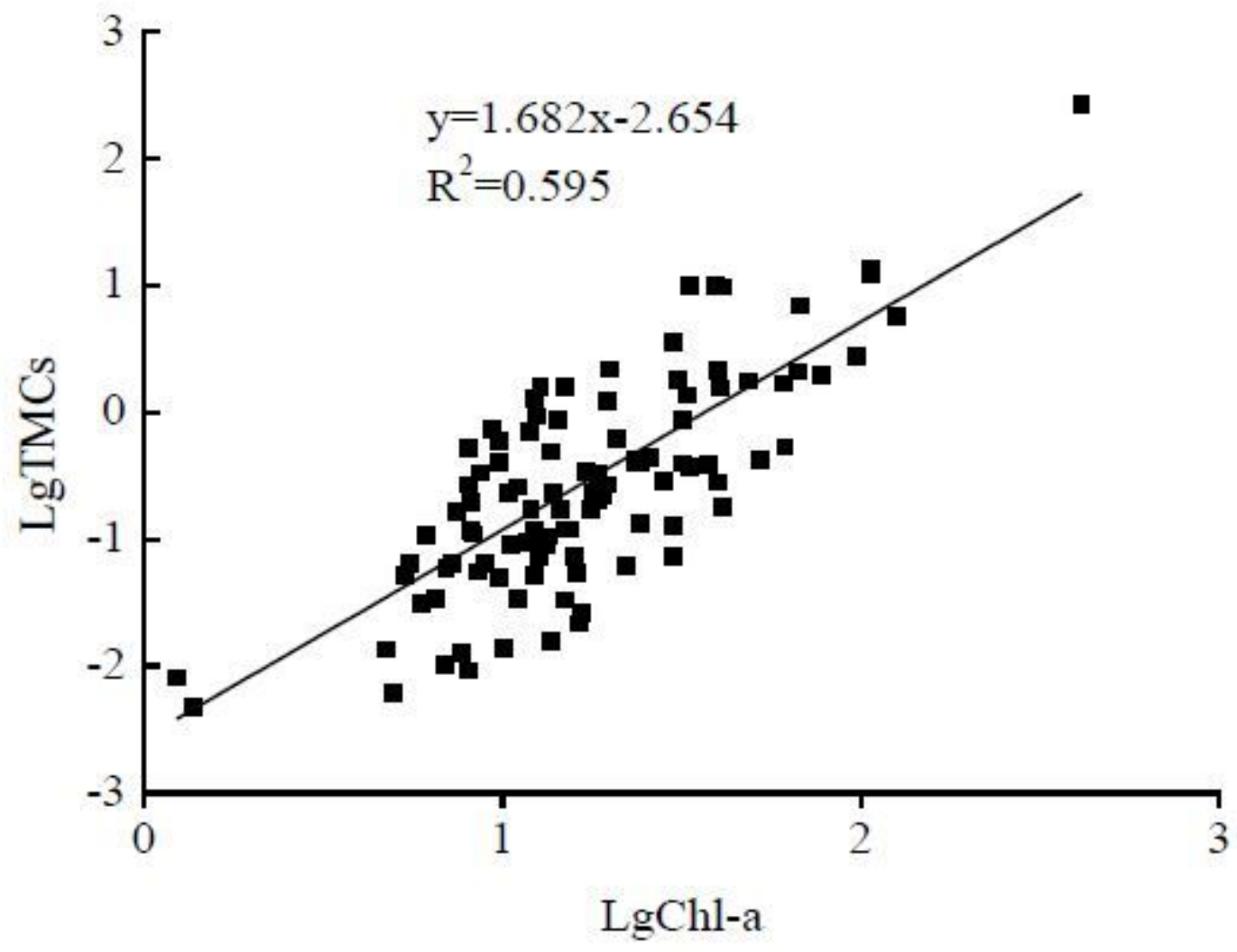

Figure 6

Correlation between TMCs and Chl-a of Lake Taihu 